Research paper

\title{
Effect of surface coating on the biodistribution profile of gold nanoparticles in the rat
}

\author{
Tiago Morais ${ }^{\mathrm{a}}$, Maria Elisa Soares ${ }^{\mathrm{a}}$, José Alberto Duarte ${ }^{\mathrm{b}}$, Leonor Soares ${ }^{\mathrm{c}}$, Sílvia Maia ${ }^{\mathrm{d}}$, Paula Gomes ${ }^{\mathrm{d}}$, \\ Eulália Pereira ${ }^{c}$, Sónia Fraga ${ }^{a}$, Helena Carmo ${ }^{a}$, Maria de Lourdes Bastos ${ }^{a, *}$ \\ ${ }^{\text {a }}$ REQUIMTE, Laboratory of Toxicology, Department of Biological Sciences, University of Porto, Porto, Portugal \\ ${ }^{\mathrm{b}}$ CIAFEL, University of Porto, Porto, Portugal \\ ${ }^{\mathrm{c}}$ REQUIMTE, Department of Chemistry and Biochemistry, University of Porto, Porto, Portugal \\ ${ }^{\mathrm{d}}$ CIQUP, Department of Chemistry and Biochemistry, University of Porto, Porto, Portugal
}

\section{A R T I C L E I N F O}

\section{Article history:}

Received 9 March 2011

Accepted in revised form 7 September 2011

Available online 16 September 2011

\section{Keywords:}

AuNPs

Functionalization

Biodistribution

GFAAS

Intravenous injection

Rat

\begin{abstract}
A B S T R A C T
Successful application of gold nanoparticles (AuNPs) in biomedicine requires extensive safety assessment for which biokinetic studies are crucial.

We evaluated the biodistribution of AuNPs $(\sim 20 \mathrm{~nm})$ with different surface coatings: citrate, 11-MUA and 3 pentapeptides, CALNN, CALND and CALNS, after i.v. administration to rats (0.6-1 mg Au/kg). Biodistribution was evaluated based on Au tissue content measured by GFAAS.

Citrate-AuNPs were rapidly removed from circulation with $60 \%$ of the injected dose depositing in the liver. Thirty minutes post-injection, the lungs presented about $6 \%$ of the injected dose with levels decreasing to $0.7 \%$ at $24 \mathrm{~h}$. Gold levels in the spleen were of $2.6 \%$. After $24 \mathrm{~h}$, liver presented the highest Au level, followed by spleen and blood.

A similar biodistribution profile was observed for MUA-coated AuNPs compared to Cit-AuNPs at $24 \mathrm{~h}$ post-injection, while significantly higher levels of peptide-capped AuNPs were found in the liver (74$86 \%$ ) accompanied by a corresponding decrease in blood levels.

TEM analysis of liver slices showed AuNPs in Kupffer cells and hepatocytes, trapped inside endosomes. Our data demonstrate that AuNPs are rapidly distributed and that the liver is the preferential accumulation organ. Peptide capping significantly increased hepatic uptake, showing the influence of AuNPs functionalization in biodistribution.
\end{abstract}

(c) 2011 Elsevier B.V. All rights reserved.

\section{Introduction}

Nanotechnology has quickly developed in the last few years, giving birth to nanomaterials, with application in areas including, textile, electronics, cosmetics and medicine. Due to unique optical and thermal properties, gold nanoparticles (AuNPs) constitute promising candidates in biomedicine to be applied in diagnostic aid [1], drug and gene delivery [2] and photothermal cancer therapy $[3,4]$. However, despite great potential, concerns regarding their safety have been raised and need to be properly addressed.

Abbreviations: 11-MUA, 11-mercaptoundecanoic acid; Au, gold; AuNPs, gold nanoparticles; CALND, Cys-Ala-Leu-Asn-Asp; CALNN, Cys-Ala-Leu-Asn-Asn; CALNS, Cys-Ala-Leu-Asn-Ser; DLS, Dynamic Light Scattering; i.p., intraperitoneal; i.v. intravenous; GFAAS, Graphite Furnace Atomic Absorption Spectrometry; NPs, nanoparticles; PEG, polyethylene glycol; RES, reticuloendothelial system; SEM, standard error of the mean; TEM, transmission electron microscopy; XPS, photoelectron spectroscopy.

* Corresponding author. REQUIMTE, Laboratory of Toxicology, Department of Biological Sciences, Faculty of Pharmacy, University of Porto, Rua Aníbal Cunha 164, 4099-030 Porto, Portugal. Tel.: +351 222078979; fax: +351 222003977.

E-mail address: mlbastos@ff.up.pt (Maria de Lourdes Bastos).
In safety assessment, biokinetic studies are crucial to understand how the different properties of the AuNPs affect their biodistribution profile, residence time, metabolism and elimination from the organism. Factors such as shape, size, surface coating and charge affect their physicochemical properties and are therefore expected to influence interactions with biological systems [5]. Reports on in vivo biodistribution of AuNPs are so far scarce and mainly focused on the kinetics of citrate-coated AuNPs after intravenous (i.v.) injection in rat [6,7] and mouse [8-10]. The bioavailability of orally administered AuNPs has also been studied in these animal models [10-12]. These studies have shown that size is one of the major determinants of biodistribution $[7,9,13]$. Also, the liver and spleen have been consistently found to be the main reservoir organs for these metallic NPs $[6,7,9,14,15]$ that are rapidly removed from the systemic circulation by the reticuloendothelial system (RES).

Functionalization through the addition of ligands on the surface of the AuNPs is of great interest as capping can confer some stealth capacity to remain undetected by the RES, thus prolonging their half-life in the bloodstream [16]. In addition, coating can also be employed as a targeting strategy to guide the NPs to a desired 
organ (e.g. brain) [17]. These capping agents can be varied in nature including polymers like polyethylene glycol (PEG) [16] and peptides [18]. Peptides as surface capping agents of AuNPs are advantageous as they can increase stability, biocompatibility and solubility in water [18]. However, knowledge on how these peptides interact and pack on a NP surface and how their anchorage affects molecular recognition of the biological target and the stability of the NPs is still scarce [19]. Studies on PEG-coated AuNPs biodistribution have shown that these NPs exhibit longer blood circulation times both in mice $[13,14,20,21]$ and in rats [22] compared to their uncoated counterparts. Nevertheless, liver and spleen remained the preferential sites of the accumulation of the PEG-AuNPs. Recently, a study by Guerrero et al. [23] demonstrated that conjugation of the amphipathic peptide CLPFFD to the AuNP surface increased in vivo brain delivery, while simultaneously reducing its retention in the spleen 1 and $2 \mathrm{~h}$ after intraperitoneal (i.p.) injection in the rat, as compared with citrate-coated AuNPs of the same size. These studies demonstrate that functionalization affects NPs in vivo kinetics and biodistribution. Hence, the present study aimed to evaluate the effect of surface coating on the biodistribution of AuNPs in the rat after a single i.v. administration. Five different coatings were investigated including (i) citrate, (ii) 11mercaptoundecanoic acid (11-MUA) and the pentapeptides, (iii) Cys-Ala-Leu-Asn-Asn (CALNN), (iv) Cys-Ala-Leu-Asn-Ser (CALNS) and (v) Cys-Ala-Leu-Asn-Asp (CALND). Citrate and 11-MUA were selected since these are the most common capping agents for AuNPs, whereas the pentapeptides have been considered particularly resistant to aggregation and precipitation in complex media [24]. The gold $(\mathrm{Au})$ content in all the collected tissues was quantified by Graphite Furnace Atomic Absorption Spectrometry (GFAAS). The AuNPs translocation from the systemic circulation into the liver and their hepatic subcellular localization was further evaluated by transmission electron microscopy (TEM).

\section{Materials and methods}

\subsection{Reagents and standards}

All chemicals used were of high purity or analytical grade. Nitric acid $\left(\mathrm{HNO}_{3}\right)$, hydrogen peroxide $\left(\mathrm{H}_{2} \mathrm{O}_{2}\right)$, palladium (II) nitrate $\left[\mathrm{Pd}\left(\mathrm{NO}_{3}\right)_{2}\right]$, magnesium nitrate $\left[\mathrm{Mg}\left(\mathrm{NO}_{3}\right)_{2}\right]$ and hydrochloric acid $(\mathrm{HCl})$ were purchased from Merck (Germany). Gold pure calibration standard was obtained from Perkin-Elmer (USA). Tetrachloroauric acid $\left(\mathrm{HAuCl}_{4} ; \sim 30 \mathrm{wt} \%\right)$, sodium citrate $\left(\mathrm{Na}_{3} \mathrm{Cit}\right)$ and 11-MUA were purchased from Sigma-Aldrich (Spain). The pentapeptides CALNN, CALND and CALNS were synthesized with a cysteine amino acid at the N-terminus for binding onto the AuNPs. Na-Fmoc-protected amino acids and Fmoc-Asn(Trt)-Wang resin used for peptide synthesis were from Novabiochem (VWR International), whereas solvents [N,N-dimethylformamide (DMF) and dichloromethane (DCM)] as well as reagents for amino acid coupling [N,N-diisopropylcarbodiimide, (DIC)] and deprotection (piperidine) were all from Sigma-Aldrich (Spain).

\subsection{Synthesis and characterization of AuNPS}

Gold nanoparticles (AuNPs) were synthesized under sterile conditions according to the Turkevich method $[25,26]$ with slight modifications. Briefly, $62.5 \mathrm{~mL}$ of $1.4 \mathrm{mM} \mathrm{HAuCl}_{4}$ was brought to the boil while stirring in a round-bottom flask, and $6.25 \mathrm{~mL}$ of a solution of $36.8 \mathrm{mM} \mathrm{Na}_{3}$ Cit was quickly added and heated for another $15 \mathrm{~min}$. The solution was then allowed to cool at room temperature. Exchange of the capping agent was performed as previously described [24], using a molar ratio capping agent/ [AuNP] of 120. Four capping agents were employed: 11-MUA and
3 pentapeptides, CALNN, CALNS and CALND. CALNN sequence is constituted by an $\mathrm{N}$-terminal cysteine $(\mathrm{C})$ residue followed by an alanine $(\mathrm{A})$, leucine $(\mathrm{L})$ and two asparagine $(\mathrm{N})$ residues. CALNS and CALND share the initial sequence of CALNN, only differing in its C-terminal residues, serine (S) and aspartic acid (D), respectively.

The peptides (C-terminal carboxyl) were assembled by classical Fmoc/tBu solid-phase peptide synthesis methodologies [27], on a pre-loaded Fmoc-Asn(Trt)-Wang resin [28]. In brief, after the removal of the Fmoc-protecting group from the pre-loaded resin with $20 \%$ piperidine in DMF, the remaining four amino acids were sequentially coupled in the $C \rightarrow N$ direction by means of standard coupling + deprotection cycles. All the coupling reactions were carried out during ca. $60 \mathrm{~min}$, using 5-M excesses of both the relevant Fmoc-protected amino acid and the coupling reagent (DIC) and using DCM or DCM/DMF mixtures as solvents. Deprotection reactions were done by treatment of the resin with $20 \%$ piperidine in DMF (1 min + $20 \mathrm{~min})$. Both coupling and deprotection were repeated until completion, which was verified by the ninhydrin or Kaiser assay [29]. After being assembled, the peptides were fully deprotected and cleaved from the resin by acidolysis $(3 \mathrm{~h})$ of the peptidyl-resin using a trifluoroacetic acid (TFA)-based cocktail [27] containing water and triisopropylsilane (TIS) as scavengers (TFA/ $\mathrm{H}_{2} \mathrm{O} /$ TIS 95:2.5:2.5 v/v/v). The crude product was purified by reverse-phase liquid chromatography, and the final product was analyzed by HPLC, ESI-IT MS and amino acid analysis.

Before utilization, NPs were washed $(3 \times)$ by centrifugation in centricon filter units (cut-off $30 \mathrm{kDa}$ ) followed by dispersion in water. Gold nanoparticle concentration was determined by UV/ Vis spectroscopy by the method of Haiss et al. [30]. Concentration of $\mathrm{Au}$ in the suspensions to be injected in the rats was determined by GFAAS. The average particle size of the initial batch (citrate) was determined by TEM using a HITACHI H-8100 microscope operated at $200 \mathrm{kV}$. The hydrodynamic diameter and zeta potential were measured by Dynamic Light Scattering (DLS) using a Zeta Sizer Nano ZS (Malvern Instruments, Ltd.), with a laser $4 \mathrm{mWHe-Ne}$ (633 nm), at $25^{\circ} \mathrm{C}$. Photoelectron spectroscopy (XPS) experiments were performed in a VG Scientific ESCALAB 200A spectrometer using non-monochromatic $\mathrm{Al} \mathrm{K} \alpha$ radiation (1486.6 eV, Materials Centre of the University of Porto, CEMUP). Corrections for sample charge were made by taking the $\mathrm{C} 1 \mathrm{~s}$ band at $285.0 \mathrm{~V}$ as internal standard. The colloidal solutions for XPS measurements were centrifuged at $60,000 \mathrm{rpm}$ for $10 \mathrm{~min}$ at room temperature, and the pellet was deposited on a graphite support.

\subsection{Animals and experimental design}

Male Wistar rats (Charles River Laboratories, Barcelona, Spain) with a body weight ranging from 200 to $300 \mathrm{~g}$ were used in this study. All the procedures were carried out in accordance with the Guide for the Care and Use of Laboratory Animals from the Institute for Laboratory Animal Research [31]. The animals were housed in metabolic cages, with a temperature and humidity controlled environment. Food and water were provided ad libitum and animals were subjected to a $12 \mathrm{~h}$ light/dark cycle. Rats were divided into five experimental groups ( $n=4$ per group) and a control group $(n=2)$. The animals were lightly anaesthetized with sodium thiopental (i.p., $30 \mathrm{mg} / \mathrm{kg}$ ), prior to the injection of AuNPs. The AuNPs suspensions were sonicated in an ultrasound bath (Bandelin Sonorex RK $100 \mathrm{H}$ ) for 5 min to ensure complete dispersion of the AuNPs. In order to accurately determine the injected dose and account for the volume of suspension left in the syringe, two aliquots of the AuNPs suspensions were taken. One of the aliquots was injected into the animal and the other was discarded to a vial for determination of the Au content by GFAAS. The amount of solution remaining in the syringe dead space did not change significantly 
among the experiments, which ensures the reproducibility of the injected dose. The tested dose for each different type of functionalized AuNPs differed slightly due to variations in the Au concentration between batches (Table 1). Pilot experiments showed that the injection procedure is crucial for the rigorous administration of AuNPs solutions, being the volume injected determinant to the amount retained in the injection point. We verified that in order to obtain consistent results the volume of the AuNPs suspensions and the velocity of injection required standardization. Thus, we chose to inject the same volume of the suspension instead of adjusting the volume to obtain the same dose. Therefore, a single injection of $1 \mathrm{~mL}$ of each suspension of AuNPs (citrate-, MUA-, CALNN-, CALNS- or CALND-coated) was slowly administered in the tail vein at an accurate dose of $\mathrm{Au}$ in the range of $0.6-1 \mathrm{mg} / \mathrm{kg}$ body weight. In consequence, for comparisons, all data calculations were made in terms of\% of the injected dose. The control group $(n=2)$ received $1 \mathrm{~mL}$ of a saline solution $(0.9 \% \mathrm{NaCl})$.

At the selected time points ( $30 \mathrm{~min}, 2 \mathrm{~h}, 6 \mathrm{~h}$ and $24 \mathrm{~h}$ for CitAuNPs and $24 \mathrm{~h}$ for the functionalized AuNPs), rats were anaesthetized with sodium thiopental (i.p., $60 \mathrm{mg} / \mathrm{kg}$ ) and sacrificed. Blood was withdrawn into heparinized tubes, and organs/tissues including heart, liver, lung, spleen, kidney, testis, small intestine (duodenum), bone (shaft of femur), skeletal muscle (quadricepts femoris), brain and tail were collected. Urine and feces were separately collected in the metabolic cages. All surgical instruments were extensively washed throughout the procedure to avoid crosscontamination. The organs were washed in saline solution $(\mathrm{NaCl}$ $0.9 \%$ ), dried in blotting paper and stored at $-80^{\circ} \mathrm{C}$ until analysis. Whole blood was stored at $4-6{ }^{\circ} \mathrm{C}$.

\subsection{Analytical procedure for determination of gold in biological samples}

\subsubsection{Digestion of biological samples}

Samples were weighed on a precision balance (Mettler Toledo PB302, Germany), followed by acid digestion in Teflon containers with a mixture of $65 \% \mathrm{HNO}_{3}$ and $30 \% \mathrm{H}_{2} \mathrm{O}_{2}$ (4:1). Five milliliters of blood, $1 \mathrm{~g}$ of homogenized liver and the whole tissue of heart, lung, spleen, kidney, testis, duodenum, shaft of femur, skeletal muscle (quadricepts femoris), brain and tail tissues were taken for digestion. After digestion at $105^{\circ} \mathrm{C}$ for $24 \mathrm{~h}$, the samples were allowed to cool at room temperature and $37 \% \mathrm{HCl}$ was added. Then, the samples were placed again in the oven at $105^{\circ} \mathrm{C}$ for $24 \mathrm{~h}$. At the end of the incubation time, samples were transferred into a tube and stored in the dark at room temperature, prior to the Au quantification.

\subsubsection{Validation of the method}

For calibration purposes, a stock solution of $\mathrm{Au}(1000 \mu \mathrm{g} / \mathrm{mL})$ and its corresponding dilutions were used to determine the linear- ity range $(0.65-50 \mathrm{ng} / \mathrm{mL})$ and to evaluate the limits of detection and quantification, which were 0.65 and $2.15 \mathrm{ng} / \mathrm{mL}$, respectively. The accuracy of the method was evaluated by the standard additions method in liver, lung, spleen, kidney and blood of untreated rats. The values expressed as\% of recovery ranged from 85.8 to 109. The precision expressed as\% cv ranged from 1.4 to 6.4 .

\subsubsection{Graphite Furnace Atomic Absorption Spectrometry (GFAAS)}

Elemental gold content of the acid-digested samples was determined by GFAAS using a Perkin-Elmer AAnalyst 600 Atomic Absorption Spectrophotometer (USA) equipped with an autosampler. Analyses were carried out at $242.8 \mathrm{~nm}$, and the readings were taken by using the peak area. The autosampler was programmed to pipette sequentially $10 \mu \mathrm{L}$ of the modifier [ $3 \mathrm{~g} / \mathrm{L} \mathrm{Pd}\left(\mathrm{NO}_{3}\right)_{2}+2 \mathrm{~g} / \mathrm{L}$ $\mathrm{Mg}\left(\mathrm{NO}_{3}\right)_{2}$ ] followed by $20 \mu \mathrm{L}$ of the standard solution/sample solution and to dispense them together onto the platform. Each digested sample was further diluted suitably, depending on the tissue type and amount using $0.2 \% \mathrm{HCl}$ prior to analysis and thoroughly vortexed before autosampler was withdrawn. All GFAAS analyses were conducted at an ashing temperature of $800{ }^{\circ} \mathrm{C}$, at an atomization temperature of $1800^{\circ} \mathrm{C}$ and with Zeeman background correction.

\subsection{Transmission electron microscopy (TEM) of biological samples}

Transmission electron microscopy was performed to assess the uptake and subcellular localization of AuNPs in the liver tissue. Slices of liver from the animals sacrificed $24 \mathrm{~h}$ post-injection (one animal per group) were randomly removed and fixed with $2.5 \%$ glutaraldehyde in $0.1 \mathrm{M}$ sodium cacodylate buffer for $4 \mathrm{~h}$. The specimens were postfixed with $2 \%$ osmium tetroxide, dehydrated through graded alcohol solutions and embedded in Epon. Ultrathin sections (100 nm) mounted on copper grids (300 mesh) were contrasted with uranyl acetate and lead citrate for TEM analysis (Zeiss EM 10A; Carl Zeiss, Oberkochen, Germany) at an accelerating voltage of $60 \mathrm{kV}$. To obtain a global characterization of the liver, several grids were prepared (5-8 grids per animal, each one having 3-4 sectioning cuts) from the different hepatic lobes.

\subsection{Statistical analysis}

Results are expressed as mean \pm the standard error of the mean (SEM) from four independent experiments. Statistical analysis was performed using the SigmaPlot 11 software. Non-parametric tests and comparisons between groups were performed with the Kruskal-Wallis test (one-way ANOVA on ranks) followed by the Student-Newman-Keuls post hoc test. Significance was accepted at a $p$ value $\leqslant 0.05$.

Table 1

Main characteristics of the AuNPs used in this study. The average size and zeta potential of the AuNPs were determined by DLS. The Au content of the suspensions was determined by GFAAS

\begin{tabular}{lllll}
\hline NP coating & Hydrodynamic radius $^{\mathrm{a}}(\mathrm{nm})$ & Zeta potential $^{\mathrm{b}}(\mathrm{mV})$ & {$\left[^{\mathrm{NP}}\right]^{\mathrm{c}}(\mathrm{nM})$} & 4.67 \\
\hline Citrate & $22.4(5.7)$ & $-44.7 \pm 7.5$ & 4.44 & $249.0 \pm 35.3$ \\
MUA & $33.2(9.8)$ & $-37.3 \pm 8.4$ & 3.45 & $236.5 \pm 15.4$ \\
CALNN & $33.7(9.6)$ & $-47.1 \pm 6.0$ & 2.85 & $152.2 \pm 14.5$ \\
CALND & $35.1(9.9)$ & $-43.6 \pm 9.2$ & 2.96 & $184.0 \pm 25.5$ \\
CALNS & $34.9(9.6)$ & $-40.5 \pm 7.0$ & & $158.1 \pm 6.9$ \\
\hline
\end{tabular}

\footnotetext{
a The values in parenthesis are polydispersion indexes.

b Results are expressed as means \pm standard deviation.

c The concentration of NPs was determined by UV/Vis for the citrate-AuNPs and estimated for the other NPs.

d The concentration of $\mathrm{Au}$ of the injected colloidal suspensions were determined by GFAAS. Results are expressed as means \pm standard error of the mean.
} 


\section{Results}

\subsection{Synthesis and characterization of AuNPs}

The main characteristics of the different negatively charged AuNPs used in our study are summarized in Table 1 and Fig. 1. Spherical citrate-stabilized AuNPs (Cit-AuNPs) were prepared as previously described [26] in strictly aseptic conditions. The average NP diameter measured by TEM was $18.4 \pm 4.9 \mathrm{~nm}$ ( $n=134 \mathrm{NPs}$ ). This agrees well with the hydrodynamic diameter determined by DLS, shown in Table 1 . The difference in the average diameters determined by the two techniques is expected considering that TEM measures the size of the electron-dense Au core, whereas DLS also measures the capping agent shell and the hydration sphere of the NPs. After exchange of the capping agent, there is a small increase in the hydrodynamic diameter and polydispersion index, probably due to the different surface properties imparted by the capping agents. Zeta potential of the colloidal dispersions of NPs was also determined, and the results are shown in Table 1. All the NPs show a high negative surface charge due to the negatively charged carboxylate moiety of MUA and the peptides. It is to be noted that the three peptides used are expected to adsorb at the surface of the NPs through the cysteine residue at the N-terminal, with the anionic C-terminal oriented towards the solution.

To confirm the exchange of the capping agent for the three peptides, XPS analysis of the NPs was performed, showing the presence of $\mathrm{Au}$ and $\mathrm{S}$. The binding energies measured (84.0 and $87.7 \mathrm{eV}$ for Au $4 \mathrm{f} 7 / 2$ and $4 \mathrm{f5} / 2$, respectively, and $162 \mathrm{eV}$ for S2p) are typical of AuNPs with thiolate capping agents [32]. Relative atomic amounts of sulfur (CALNN: 3.93\%; CALND: 6.69\%; CALNS 3.08\%) and Au (CALNN: 89.3\%; CALND: 89.2\%; CALNS 89.1\%) are within the range usually observed for AuNPs with thiolate capping agents.

The concentration of Cit-AuNPs was evaluated by UV/Vis spectroscopy using the method of Haiss et al. [30] and estimated for the other NPs (Table 1). Before injection, the Au contents of the AuNPs suspensions ([Au] in $\mu \mathrm{g} / \mathrm{mL}$ ) were determined by the validated GFAAS (Table 1).

\subsection{Biodistribution of AuNPs in the rat}

\subsubsection{Biodistribution profile of the citrate-coated AuNPs}

The biodistribution profile of the AuNPs in the rat organism was evaluated based on the Au content present in the biological samples collected from AuNPs-administered rats. The elemental gold was determined by GFAAS, a technique considered to be suitable to monitor the biodistribution of AuNPs [33]. The kinetics of distribution of citrate-coated AuNPs (Cit-AuNPs) at the selected time points $(0.5,2,6$ and $24 \mathrm{~h})$ in $\mathrm{ng} / \mathrm{g}$ organ is shown in Table 2. Analyzing the amount of Au found, the highest concentrations were found in the liver $(14,801 \pm 839 \mathrm{ng} / \mathrm{g})$ followed by the spleen $(5480 \pm 1116 \mathrm{ng} / \mathrm{g})$. The lung showed a high Au content $30 \mathrm{~min}$ after injection ( $9228 \pm 3316 \mathrm{ng} / \mathrm{g}$ ), but levels decreased very rapidly with time down to $1886 \pm 1169 \mathrm{ng} / \mathrm{g}$ at $24 \mathrm{~h}$. The liver was the preferential site for accumulation of the citrate-coated AuNPs, with values as high as $60 \%$ of the injected dose (Table 3 ). In the spleen, Au was present at appreciable levels, similar to those found in the tail, of about $3 \%$ of the injected dose. Traceable amounts of
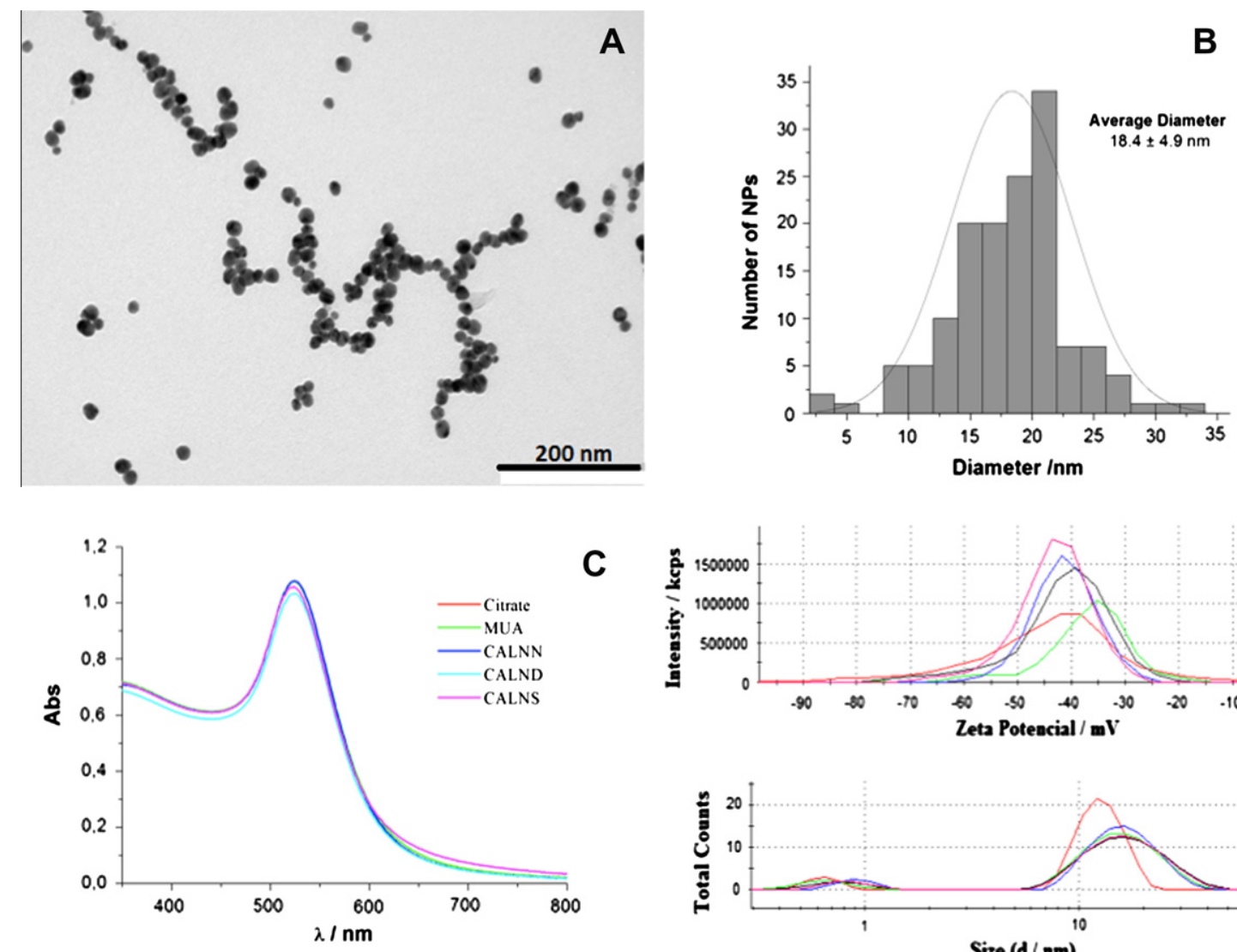

C
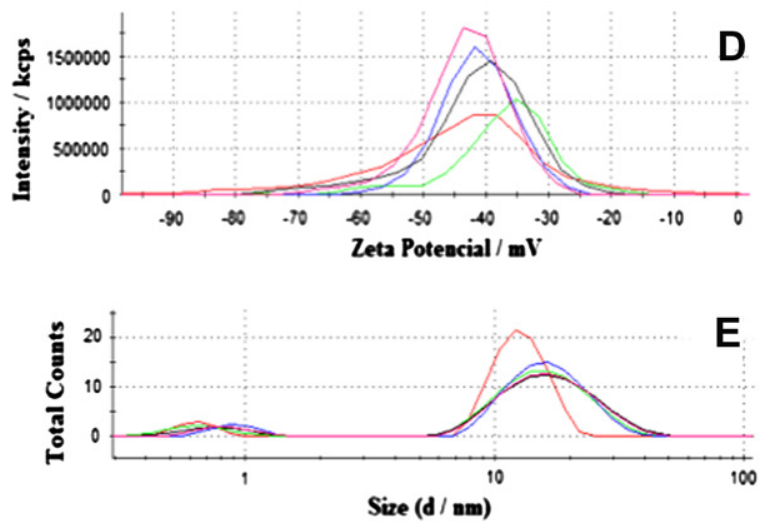

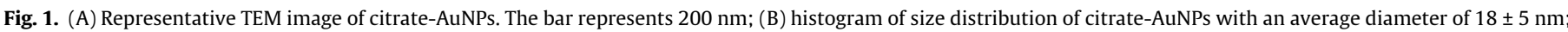

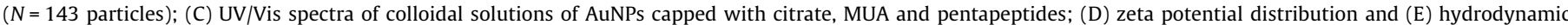

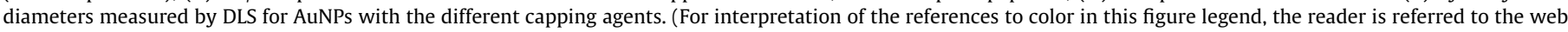
version of this article.) 
Table 2

Gold distribution in the analyzed rat organs 0.5-24 h after i.v. injection of Cit-AuNPs and $24 \mathrm{~h}$ after i.v. injection of the functionalized AuNPs (expressed as ng/g tissue).

\begin{tabular}{|c|c|c|c|c|c|c|c|c|}
\hline \multirow[t]{3}{*}{ Tissue } & \multicolumn{8}{|c|}{ Gold concentration (ng/g tissue) } \\
\hline & \multicolumn{4}{|l|}{ Cit-AuNPs } & \multirow{2}{*}{$\begin{array}{l}\text { MUA-AuNPs } \\
24 \mathrm{~h}\end{array}$} & \multirow{2}{*}{$\begin{array}{l}\text { CALNN-AuNPs } \\
24 \mathrm{~h}\end{array}$} & \multirow{2}{*}{$\begin{array}{l}\text { CALND-AuNPs } \\
24 \mathrm{~h}\end{array}$} & \multirow{2}{*}{$\begin{array}{l}\text { CALNS-AuNPs } \\
24 \mathrm{~h}\end{array}$} \\
\hline & $0.5 \mathrm{~h}$ & $2 \mathrm{~h}$ & $6 \mathrm{~h}$ & $24 \mathrm{~h}$ & & & & \\
\hline Liver & $15419 \pm 1186$ & $16810 \pm 1202$ & $16341 \pm 2046$ & $14801 \pm 839$ & $13884 \pm 1269$ & $9970 \pm 3214$ & $15436 \pm 349$ & $12153 \pm 542$ \\
\hline Spleen & $10570 \pm 1972$ & $7352 \pm 1796$ & $7282 \pm 1834$ & $5480 \pm 1116$ & $8079 \pm 1790$ & $6059 \pm 671$ & $7572 \pm 1797$ & $4165 \pm 412$ \\
\hline Lungs & $9228 \pm 3316$ & $1045 \pm 102$ & $1370 \pm 296$ & $1886 \pm 1169$ & $975 \pm 368$ & $739 \pm 71$ & $1838 \pm 1112$ & $814 \pm 89$ \\
\hline Blood & $134 \pm 42$ & $392 \pm 246$ & $260 \pm 92$ & $189 \pm 67$ & $153 \pm 91$ & $25 \pm 12$ & $21 \pm 9$ & $38 \pm 6$ \\
\hline Heart & $30 \pm 15$ & $114 \pm 47$ & $79 \pm 42$ & $151 \pm 53$ & $38 \pm 24$ & $20 \pm 5$ & $51 \pm 28$ & $25 \pm 9$ \\
\hline Kidney & $41 \pm 4$ & $178 \pm 134$ & $101 \pm 74$ & $129 \pm 37$ & $41 \pm 21$ & $150 \pm 50$ & $60 \pm 27$ & $15 \pm 9$ \\
\hline Small intestine & $12 \pm 3$ & $160 \pm 57$ & $82 \pm 41$ & $43 \pm 17$ & $19 \pm 8$ & $187 \pm 72$ & $9 \pm 5$ & $196 \pm 73$ \\
\hline Brain & $8 \pm 3$ & $26 \pm 10$ & $59 \pm 32$ & $68 \pm 53$ & $36 \pm 12$ & $9 \pm 5$ & $38 \pm 10$ & $<\mathrm{LQ}$ \\
\hline Bone & $1005 \pm 937$ & $935 \pm 541$ & $339 \pm 103$ & $575 \pm 410$ & $77 \pm 51$ & $94 \pm 40$ & $41 \pm 17$ & $42 \pm 17$ \\
\hline Muscle & $26 \pm 16$ & $112 \pm 50$ & $74 \pm 62$ & $51 \pm 51$ & $37 \pm 17$ & $10 \pm 8$ & $37 \pm 21$ & $39 \pm 16$ \\
\hline Testis & $15 \pm 8$ & $15 \pm 16$ & $53 \pm 30$ & $<\mathrm{LQ}$ & $<\mathrm{LQ}$ & $<\mathrm{LQ}$ & $16 \pm 11$ & $<\mathrm{LQ}$ \\
\hline Tail & $941 \pm 321$ & $596 \pm 164$ & $419 \pm 51$ & $852 \pm 236$ & $1830 \pm 779$ & $870 \pm 346$ & $481 \pm 144$ & $484 \pm 164$ \\
\hline
\end{tabular}

The results are presented as means \pm SEM $(n=4)$; LQ (limit of quantification).

Table 3

Kinetics of Au distribution in the analyzed rat organs after i.v. injection of Cit-AuNPs expressed as\% of injected dose.

\begin{tabular}{|c|c|c|c|c|}
\hline \multirow[t]{2}{*}{ Tissue } & \multicolumn{4}{|c|}{$\%$ of injected gold } \\
\hline & $0.5 \mathrm{~h}$ & $2 \mathrm{~h}$ & $6 \mathrm{~h}$ & $24 \mathrm{~h}$ \\
\hline Liver & $57.75 \pm 2.28$ & $68.43 \pm 7.01$ & $74.53 \pm 6.62$ & $57.94 \pm 2.57$ \\
\hline Spleen & $2.55 \pm 0.38^{a}$ & $2.06 \pm 0.50^{\mathrm{a}}$ & $2.13 \pm 0.31^{a}$ & $1.34 \pm 0.23^{\mathrm{a}}$ \\
\hline Lung & $5.58 \pm 2.40^{\mathrm{a}}$ & $0.47 \pm 0.04^{\mathrm{a}, \mathrm{b}, \mathrm{c}, \mathrm{d}}$ & $0.43 \pm 0.11^{\mathrm{a}}$ & $0.72 \pm 0.44^{\mathrm{a}}$ \\
\hline Blood & $0.82 \pm 0.24^{\mathrm{a}}$ & $2.92 \pm 1.86^{\mathrm{a}}$ & $1.95 \pm 0.80^{\mathrm{a}}$ & $1.27 \pm 0.43^{\mathrm{a}}$ \\
\hline Heart & $0.01 \pm 0.00^{\mathrm{a}}$ & $0.03 \pm 0.01^{\mathrm{a}, \mathrm{b}, \mathrm{c}, \mathrm{d}, \mathrm{e}}$ & $0.03 \pm 0.01^{\mathrm{a}}$ & $0.04 \pm 0.01^{\mathrm{a}, \mathrm{b}, \mathrm{c}, \mathrm{d}, \mathrm{e}}$ \\
\hline Kidney & $0.03 \pm 0.00^{\mathrm{a}}$ & $0.13 \pm 0.10^{\mathrm{a}, \mathrm{b}, \mathrm{c}, \mathrm{d}, \mathrm{e}}$ & $0.08 \pm 0.06^{\mathrm{a}}$ & $0.08 \pm 0.02^{\mathrm{a}, \mathrm{b}, \mathrm{c}, \mathrm{d}, \mathrm{e}}$ \\
\hline Small intestine & $0.01 \pm 0.00^{\mathrm{a}}$ & $0.07 \pm 0.02^{\mathrm{a}, \mathrm{b}, \mathrm{c}, \mathrm{d}, \mathrm{e}}$ & $0.03 \pm 0.01^{\mathrm{a}}$ & $0.02 \pm 0.01^{\mathrm{a}, \mathrm{b}, \mathrm{c}, \mathrm{d}, \mathrm{e}}$ \\
\hline Muscle & $0.01 \pm 0.00^{\mathrm{a}}$ & $0.04 \pm 0.02^{\mathrm{a}, \mathrm{b}, \mathrm{c}, \mathrm{d}, \mathrm{e}}$ & $0.03 \pm 0.03^{\mathrm{a}}$ & $0.01 \pm 0.01^{\mathrm{a}, \mathrm{b}, \mathrm{c}, \mathrm{d}, \mathrm{e}}$ \\
\hline Brain & $0.01 \pm 0.00^{\mathrm{a}}$ & $0.02 \pm 0.01^{\mathrm{a}, \mathrm{b}, \mathrm{c}, \mathrm{d}, \mathrm{e}}$ & $0.05 \pm 0.03^{\mathrm{a}}$ & $0.05 \pm 0.04^{\mathrm{a}, \mathrm{b}, \mathrm{c}, \mathrm{d}, \mathrm{e}}$ \\
\hline Bone & $0.12 \pm 0.10^{\mathrm{a}}$ & $0.27 \pm 0.15^{\mathrm{a}, \mathrm{b}, \mathrm{c}, \mathrm{d}, \mathrm{e}}$ & $0.10 \pm 0.05^{\mathrm{a}}$ & $0.16 \pm 0.10^{\mathrm{a}, \mathrm{b}, \mathrm{c}, \mathrm{d}, \mathrm{e}}$ \\
\hline Testis & $0.02 \pm 0.01^{\mathrm{a}}$ & $0.02 \pm 0.02^{\mathrm{a}, \mathrm{b}, \mathrm{c}, \mathrm{d}, \mathrm{e}}$ & $0.04 \pm 0.04^{\mathrm{a}}$ & $0.00 \pm 0.01^{\mathrm{a}, \mathrm{b}, \mathrm{c}, \mathrm{d}, \mathrm{e}}$ \\
\hline Tail & $2.60 \pm 0.89^{\mathrm{a}}$ & $1.70 \pm 0.51^{\mathrm{a}}$ & $1.26 \pm 0.13^{\mathrm{a}}$ & $2.27 \pm 0.67^{\mathrm{a}}$ \\
\hline Total & $67.81 \pm 1.73$ & $73.85 \pm 5.45$ & $73.71 \pm 2.35$ & $63.91 \pm 2.89$ \\
\hline
\end{tabular}

Results are presented as means $\pm \operatorname{SEM}(n=4)$.

a 0.05 vs. Liver.

b 0.05 vs. Spleen.

c 0.05 vs. Tail.

d 0.05 vs. Blood.

e 0.05 vs. Lung.

Au were detected in the kidney and in the bone, whereas values obtained in the other tissues were very close to the limit of quantification $(2.15 \mathrm{ng} / \mathrm{g})$. Although no statistically significant differences were found in the amount of $\mathrm{Au}$ present in the organs throughout the experiment, some trends could be observed (Table 3). Thirty minutes after injection, the liver contained $57.75 \pm 2.28 \%$ of the injected Au, peaked at $6 \mathrm{~h}(74.53 \pm 6.62 \%)$ but returned to the initial values $(57.94 \pm 2.57 \%)$ at $24 \mathrm{~h}$. In the spleen, $\mathrm{Au}$ levels decreased from $2.55 \pm 0.38 \%$ at $30 \mathrm{~min}$ to $1.34 \pm 0.23 \%$ at $24 \mathrm{~h}$, showing a declining trend of Au concentration in this organ. For the studied times, the highest blood Au concentration was found at $2 \mathrm{~h}(2.36 \pm 1.48 \%)$ followed by a steady decrease $(1.14 \pm 0.40 \%$ at $24 \mathrm{~h})$. A small amount of the injected dose was retained in the tail, but no differences were observed in those values throughout the experiment. The total Au recovery in the analyzed samples of the rat organism ranged from $64 \%$ to $74 \%$ of the injected dose.

\subsubsection{Biodistribution profile of 11-MUA and pentapeptide-coated AuNPs}

The effect of 11-MUA and pentapeptide surface coating on the biodistribution profile of AuNPs was investigated $24 \mathrm{~h}$ after intravenous administration to rats. Regarding MUA-AuNPs, a similar distribution pattern to the Cit-AuNPs has been observed (Table 4).
High concentrations of Au were found in the liver, followed by tail, spleen, blood and lungs. Corrected for the corresponding injected dose, liver and spleen were the major accumulation sites for MUA-AuNPs (Fig. 2).

Although pentapeptide-coated AuNPs shared the general pattern of distribution with Cit-AuNPs, some significant differences in tissue Au contents were observed. Peptide-capped NPs were widely distributed throughout the body, mainly present in liver, spleen, and to a lesser extent in the lungs (Table 4). Twenty-four hours after injection, $77.47 \pm 2.52 \%$ of the total injected CALNDAuNPs, $86.11 \pm 7.13 \%$ of the CALNN-AuNPs and $73.66 \pm 4.84 \%$ of CALNS-AuNPs were retained in the liver (Fig. 2 and Table 4). These values were significantly higher than those found in the liver of the citrate-coated AuNPs-treated rats. A significantly lower\% of the total injected Au was observed in blood from rats exposed to CALNN$(0.32 \pm 0.13 \%)$, CALNS- $(0.38 \pm 0.07 \%)$ and CALND-AuNPs $(0.19 \pm 0.08 \%)$, in comparison with Cit-AuNPs-treated rats $(1.27 \pm 0.43 \%)$. In addition to the liver, the spleen of the CALNNAuNPs-injected rats also acts as reservoir organ as evidenced by the significantly higher contents of Au comparing to the blood levels. No differences in the Au levels retained in the tail were observed for all the functionalized AuNPs-treated rats. Also, $\mathrm{Au}$ levels found in urine and feces were always below the limit of quantification. 
Table 4

Gold concentration in the analyzed rat organs $24 \mathrm{~h}$ after i.v. injection of the AuNPs (expressed as\% of the injected dose).

\begin{tabular}{|c|c|c|c|c|c|}
\hline \multirow[t]{2}{*}{ Tissue } & \multicolumn{5}{|l|}{$\%$ of injected gold } \\
\hline & Citrate-AuNPs & MUA-AuNPs & CALNN-AuNPs & CALND-AuNPs & CALNS-AuNPs \\
\hline Liver & $57.94 \pm 2.57$ & $59.37 \pm 4.08^{\mathrm{f}, \mathrm{g}}$ & $86.11 \pm 7.13^{\mathrm{f,g}}$ & $77.47 \pm 2.52^{\mathrm{f}, \mathrm{g}}$ & $73.66 \pm 4.84^{\mathrm{f}, \mathrm{g}}$ \\
\hline Spleen & $1.34 \pm 0.23^{\mathrm{a}}$ & $2.26 \pm 0.52^{\mathrm{a}}$ & $2.79 \pm 0.30^{\mathrm{a}}$ & $2.51 \pm 0.59^{\mathrm{a}}$ & $1.88 \pm 0.13^{\mathrm{a}}$ \\
\hline Lung & $0.72 \pm 0.44^{\mathrm{a}}$ & $0.44 \pm 0.19^{a}$ & $0.53 \pm 0.06^{\mathrm{a}, \mathrm{b}, \mathrm{c}}$ & $0.88 \pm 0.6^{\mathrm{a}}$ & $0.52 \pm 0.09^{\mathrm{a}}$ \\
\hline Blood & $1.27 \pm 0.43^{\mathrm{a}}$ & $1.13 \pm 0.71^{\mathrm{a}, \mathrm{f}}$ & $0.32 \pm 0.13^{\mathrm{a}, \mathrm{b}, \mathrm{c}, \mathrm{f}}$ & $0.19 \pm 0.08^{\mathrm{a}, \mathrm{f}}$ & $0.38 \pm 0.07^{\mathrm{a}, \mathrm{f}}$ \\
\hline Heart & $0.04 \pm 0.01^{\mathrm{a}, \mathrm{b}, \mathrm{c}, \mathrm{d}, \mathrm{e}}$ & $0.01 \pm 0.01^{\mathrm{a}}$ & $0.01 \pm 0.00^{\mathrm{a}, \mathrm{b}, \mathrm{c}}$ & $0.02 \pm 0.01^{\mathrm{a}}$ & $0.01 \pm 0.00^{\mathrm{a}}$ \\
\hline Kidney & $0.08 \pm 0.02^{\mathrm{a}, \mathrm{b}, \mathrm{c}, \mathrm{d}, \mathrm{e}}$ & $0.03 \pm 0.01^{\mathrm{a}}$ & $0.20 \pm 0.07^{\mathrm{a}, \mathrm{b}, \mathrm{c}}$ & $0.05 \pm 0.02^{\mathrm{a}}$ & $0.01 \pm 0.00^{\mathrm{a}}$ \\
\hline Small intestine & $0.02 \pm 0.01^{\mathrm{a}, \mathrm{b}, \mathrm{c}, \mathrm{d}, \mathrm{e}}$ & $0.01 \pm 0.00^{\mathrm{a}}$ & $0.24 \pm 0.09^{\mathrm{a}, \mathrm{b}, \mathrm{c}}$ & $0.01 \pm 0.01^{a}$ & $0.19 \pm 0.06^{\mathrm{a}}$ \\
\hline Muscle & $0.01 \pm 0.01^{\mathrm{a}, \mathrm{b}, \mathrm{c}, \mathrm{d}, \mathrm{e}}$ & $0.01 \pm 0.00^{\mathrm{a}}$ & $0.00 \pm 0.00^{\mathrm{a}, \mathrm{b}, \mathrm{c}}$ & $0.01 \pm 0.01^{\mathrm{a}}$ & $0.03 \pm 0.02^{\mathrm{a}}$ \\
\hline Brain & $0.05 \pm 0.04^{\mathrm{a}, \mathrm{b}, \mathrm{c}, \mathrm{d}, \mathrm{e}}$ & $0.02 \pm 0.01^{\mathrm{a}}$ & $0.01 \pm 0.01^{\mathrm{a}, \mathrm{b}, \mathrm{c}}$ & $0.03 \pm 0.01^{\mathrm{a}}$ & $0.00 \pm 0.00^{\mathrm{a}}$ \\
\hline Bone & $0.16 \pm 0.10^{\mathrm{a}, \mathrm{b}, \mathrm{c}, \mathrm{d}, \mathrm{e}}$ & $0.01 \pm 0.01^{\mathrm{a}}$ & $0.07 \pm 0.03^{\mathrm{a}, \mathrm{b}, \mathrm{c}}$ & $0.03 \pm 0.01^{\mathrm{a}}$ & $0.03 \pm 0.01^{\mathrm{a}}$ \\
\hline Testis & $0.00 \pm 0.01^{\mathrm{a}, \mathrm{b}, \mathrm{c}, \mathrm{d}, \mathrm{e}}$ & $0.00 \pm 0.00^{\mathrm{a}}$ & $0.01 \pm 0.00^{\mathrm{a}, \mathrm{b}, \mathrm{c}}$ & $0.02 \pm 0.02^{\mathrm{a}}$ & $0.00 \pm 0.00^{\mathrm{a}}$ \\
\hline Tail & $2.27 \pm 0.67^{\mathrm{a}}$ & $4.58 \pm 1.90^{\mathrm{a}}$ & $3.80 \pm 1.52^{\mathrm{a}}$ & $1.63 \pm 0.55^{a}$ & $1.77 \pm 0.66^{\mathrm{a}}$ \\
\hline Total recovery & $63.91 \pm 2.89$ & $67.88 \pm 4.80$ & $94.10 \pm 8.33^{\mathrm{f,g}}$ & $82.85 \pm 2.70$ & $78.49 \pm 4.61$ \\
\hline
\end{tabular}

Results are presented as means $\pm \operatorname{SEM}(n=4)$.

a 0.05 vs. Liver;

b 0.05 vs. Spleen;

c 0.05 vs. Tail.

d 0.05 vs. Blood.

e 0.05 vs. Lung.

f 0.05 vs. Cit-AuNPs.

g 0.05 vs. MUA-AuNPs.

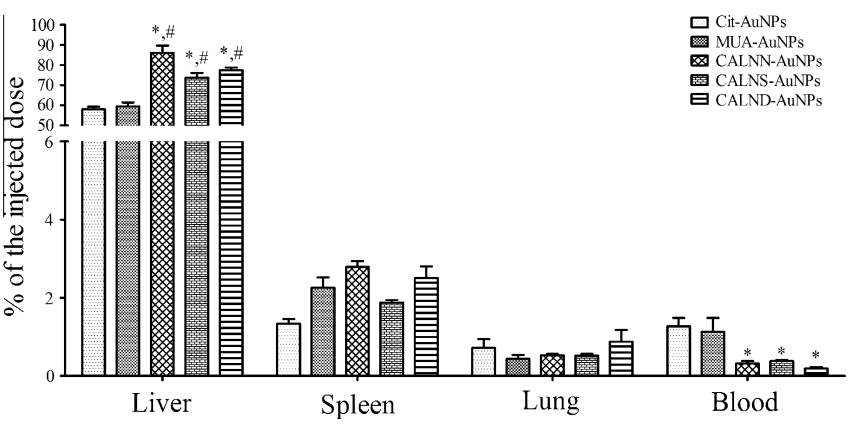

Fig. 2. Gold concentration in the liver, spleen, lung and blood, $24 \mathrm{~h}$ after i.v. injection with AuNPs (expressed as\% of the injected dose). Results are presented as mean \pm SEM ( $n=4$ per group). ${ }^{*} p<0.05$ vs. Cit-AuNPs, ${ }^{*} p<0.05$ vs. MUA-AuNPs.

Macroscopic observation of the tissues showed that no signs of toxicity were elicited in the rats by any of the tested AuNPs $24 \mathrm{~h}$ after intravenous administration. The injections were well tolerated, and rats did not exhibit alterations in behavior. Tissue size, color and morphology remained unchanged, as compared to saline-treated rats. No significant differences were seen in total body and organ weights, as compared with control animals (data not shown). No macroscopic signs of inflammation were observed.

\subsection{Uptake and subcellular localization of the AuNPs}

Translocation of the different AuNPs from systemic circulation to the liver at $24 \mathrm{~h}$ after intravenous injection was investigated by TEM. The AuNPs appeared as electron-dense deposits detected in the liver tissue, trapped inside hepatocytes (Fig. 3) and Kupffer cells (Fig. 4). A qualitative analysis of the micrographs suggested that in the hepatic tissue, all the tested AuNPs preferentially accumulate in Kupffer cells and to a lesser extent in the hepatocytes. For both type of cells, monodisperse or agglomerates of citrate-, MUA- and peptide-coated AuNPs were observed inside endosomes. Freely dispersed AuNPs in the cytosol, within the nucleus or in other cytoplasmic organelles were not detected. The electrondense material was absent in the hepatic tissue of the control animal (data not shown). Although only one animal/group has been used in this analysis, the observations were very consistent among the AuNPs-treated animals and clearly distinct from those observed in the control animal. In addition, Kupffer cells exhibited signs of necrosis, indicating possible AuNPs-induced injury. A semi-quantitative analysis of the amount of the different functionalized AuNPs internalized by the Kupffer cells was performed. Higher uptake of pentapeptide-coated AuNPs comparing to CitAuNPs was observed (Table 5), which is in agreement with the quantitative analysis of $\mathrm{Au}$.

\section{Discussion}

Safe biomedical applications of AuNPs require extensive biokinetic assessment. Increasing evidence demonstrates that not only the chemical nature but other factors such as size, shape and surface functionalization are important determinants of nanomaterial in vivo dynamics and toxicity [34-36]. The present study compared the biodistribution profile of anionic AuNPs with different surface coatings after a single i.v. administration in the rat. The administrated doses are in the range of those used in previous studies (summarized in Table 1 of [10]). The selection of the capping agents was based on previous reports on their stability and solubility in aqueous dispersions, as well as their ability to prevent nanoparticle aggregation [24,37]. Functionalization of the reference AuNPs (Cit-AuNPs) by 11-MUA and the pentapeptides CALNN, CALNS and CALND did not induce a significant change in size and surface charge (Table 1), indicating that any change in the distribution pattern of the tested AuNPs would most likely be due to surface-ligand interactions with cells and biomolecules.

The kinetic study conducted revealed that the injected Cit-AuNPs are rapidly translocated from the bloodstream into organs as shown by the higher liver, lung and spleen Au levels compared to blood levels as early as $0.5 \mathrm{~h}$ after injection. Two hours after injection, the liver and the spleen were the organs with higher contents of $\mathrm{Au}$, which is consistent with previous reports for Cit-AuNPs with similar size in rat $[6,7]$ and mice $[9,14,15]$. Our data support the notion that bare AuNPs have low ability to escape from the RES [16]. Furthermore, the relatively constant high hepatic Au levels observed during the $24 \mathrm{~h}$ indicates that Cit-AuNPs are poorly eliminated, which has also been previously described even for long-term (up to 6 months) studies in rats [6] and mice $[8,9,13]$. 

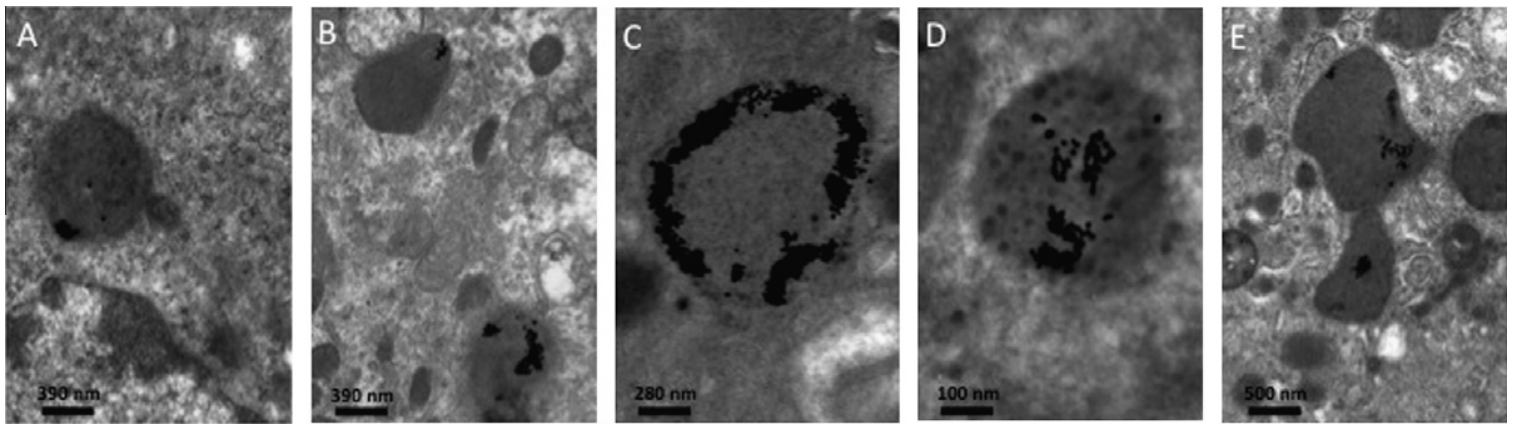

Fig. 3. Representative TEM micrographs of rat liver taken $24 \mathrm{~h}$ after the intravenous injection of Cit-AuNPs (A), MUA-AuNPs (B), CALND-AuNPs (C), CALNS-AuNPs (D) and CALNN-AuNPs (E). The AuNPs appeared as electron-dense deposits and images show clusters of AuNPs entrapped in hepatocytes' endosomes.
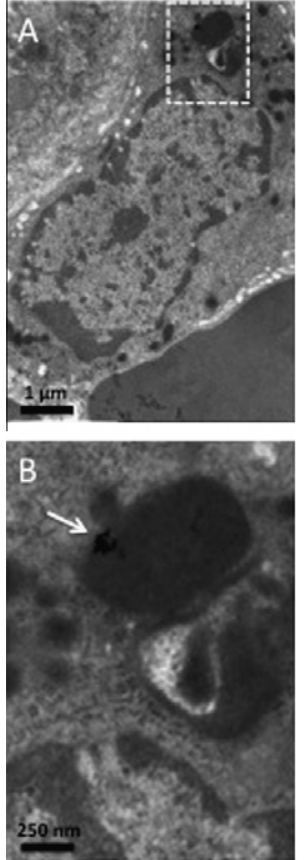
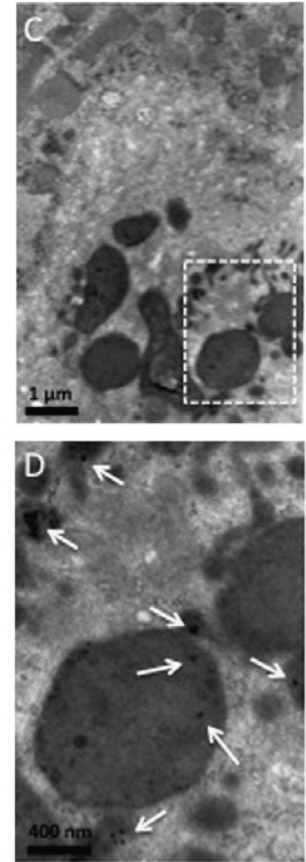
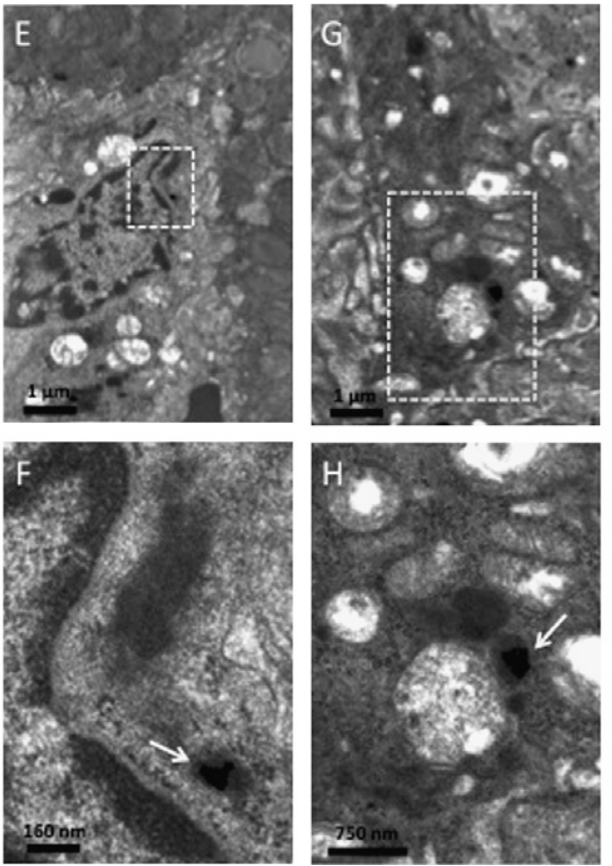
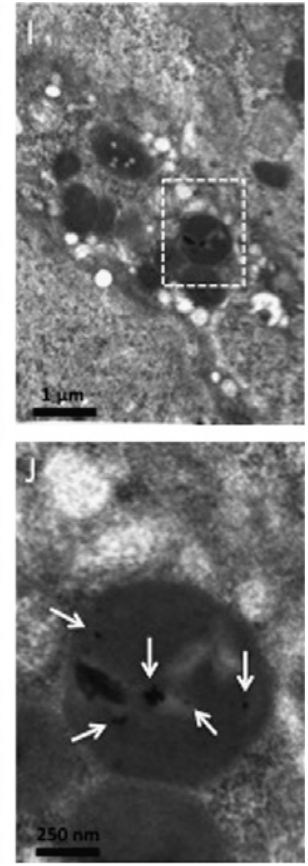

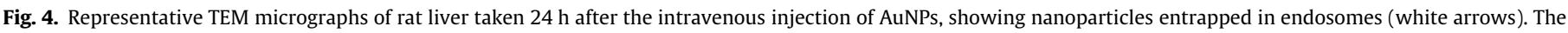

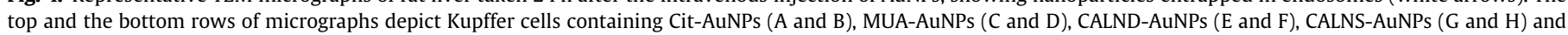
CALNN-AuNPs (I and J). The bottom micrographs correspond to the dashed square marked in the upper row.

Table 5

Semiquantitative TEM analysis of the amount of internalized AuNPs by the Kupffer cells.

\begin{tabular}{llcl}
\hline NP coating & Kupffer cells total observed & Kupffer cells containing AuNPs & \% of Kupfer cells containing AuNPs \\
\hline Citrate & 51 & 10 & 20 \\
MUA & 45 & 8 & 18 \\
CALNN & 19 & 19 & 28 \\
CALND & 55 & 15 & 27 \\
CALNS & 49 & 12 & 24 \\
\hline
\end{tabular}

Results obtained from observations of one animal/group.

The poor elimination of these AuNPs can be attributed to their relatively large size, since renal excretion would not be expected for NPs with over $5.5 \mathrm{~nm}$ average diameter [38]. In addition, a very low percentage of the initial injected Au dose remained in the blood over the time, indicating a rapid translocation of Cit-AuNPs into the tissues. Similar results have been found by others in rat $[36,39]$ and mouse [9] after i.v. administration of Cit-AuNPs. However, De Jong et al. have reported high levels of Cit-AuNPs with different sizes in the blood at $24 \mathrm{~h}$ after i.v. administration in the rat [7].
Longer circulation time and minimum uptake by the RES cells are desirable in terms of better therapeutic efficacy and targetability of the AuNPs. Several studies on the kinetics of PEG-functionalized AuNPs revealed longer plasma half-lives for these NPs $[13,14,20-22]$; however, liver and spleen remained the major reservoirs. In our study, with the exception of blood levels, MUAcoated AuNPs distribution pattern was similar to that obtained for Cit-AuNPs at $24 \mathrm{~h}$ after i.v. injection.

According to a recent study by Guerrero et al., capping AuNPs with an amphipathic peptide sequence appears to be a good strat- 
egy to improve brain delivery in the rat [23]. Regarding the peptide-functionalized AuNPs employed in our study, the general trend of distribution did not differ from the one described for Cit-AuNPs; however, increased Au levels in the liver were attained for CALNN-, CALNS- and CALND-capped AuNPs at $24 \mathrm{~h}$ post-injection, with values significantly higher than those found for Cit-AuNPs. Interestingly, this increase in the hepatic Au content was accompanied by a significant decrease in blood Au levels comparing to the observed in Cit-AuNPs-treated rats. The exact reasons for this different behavior are currently not completely clear but under investigation. It could be related to differences in stability and/or interaction with serum proteins between bare and peptide-coated AuNPs. In fact, we have previously reported that the affinity of proteins to Cit-AuNPs and to AuNPs with thiol-ligands (peptides with a terminal Cys or other organic molecules) is different, despite the fact that the functional groups at the outer-surface of the AuNPs were in both cases carboxylates [40].

Although changes in the peptide sequence could affect the stability and modify NPs interactions with biomolecules [41], no major differences were observed among the three pentapeptidefunctionalized AuNPs employed in our study. This is in line with the report by Levy et al. who found that changing the terminal amino acid of CALNN to a more negative (CALND) or neutral residue (CALNS) did not affect the stability of AuNPs comparing to CALNN-coated AuNPs [24]. In addition, Olmedo et al. [41] have shown that AuNPs functionalized with the peptide CLPFFD- $\mathrm{NH}_{2}$ have more affinity to $\beta$-amyloid fibrils than bare AuNPs supporting the view that peptide functionalization of AuNPs could enhance their interactions with biological molecules.

In our study, the percentage of Au recovery ranged from $60 \%$ to $90 \%$ of the total injected dose. This could be due to Au accumulation in other non-analyzed organs and fractions (e.g. skin, skeleton and soft tissue), which agrees with previous reports of high percentages of the injected dose of radiolabelled AuNPs found in the remaining carcass $[36,39]$. In addition, we also analyzed urine and feces, but the Au levels were below the quantification level excluding their contribution to the Au loss.

Also, the tested dose for each different type of functionalized AuNP varied slightly comparing to Cit-AuNPs. However, considering the peptide-coated AuNPs, our results show that in spite of differences in the administered dose (CALNN-, CALNS< Cit-AuNPs; CALND- $\sim$ Cit-AuNPs), no differences in hepatic accumulation among these peptide-coated AuNPs were observed. Therefore, liver accumulation seems to be increased with the peptide capping. However, the possibility that differences in dose may influence the biodistribution pattern cannot be overruled.

Accumulation of AuNPs in the liver could lead to histological changes and toxicity $[42,43]$. The TEM studies of liver tissue samples from rats exposed to the differently capped AuNPs revealed the presence of monodisperse and clusters of nanoparticles inside endosomes of both hepatocytes and Kupffer cells. Endosomal location for citrate- and CALNN-coated AuNPs has been also observed in vitro by Nativo and coworkers in HeLa cells [44]. In Kupffer cells, the preferential target for all tested AuNPs, signs of necrosis were observed.

In general, the biodistribution profile for MUA- and pentapeptide-capped AuNPs did not differ from citrate-AuNPs. The possibility of removal of the capping agent after contact with physiological media leading to the initial bare AuNPs cannot be ruled out. However, this is less likely to occur as it is expected that the capping agent remains bound due to the strong binding of thiol groups to Au surfaces, even in biological media [45]. Nevertheless, additional studies are needed to determine whether these AuNPs may induce distinct immunological or metabolic changes. Also, studies examining biodistribution for longer periods of time can provide valu- able information for a better understanding of the impact of functionalization in the AuNPs life cycle in the organism.

\section{Conclusion}

With the present study, we have shown that the biodistribution profile of Cit-AuNPs remains constant in the first $24 \mathrm{~h}$ after i.v. administration and that the liver and spleen are the preferential organs for these AuNPs uptake, followed by the lung. Our data show that functionalization of the AuNPs surface with 11-MUA, CALNN, CALND or CALNS does not induce significant changes in the general biodistribution pattern relative to the reference Cit-AuNPs. However, pentapeptide coating significantly increased accumulation in the liver while decreasing levels in circulation, which emphasizes the influence of surface coating on the potential interactions between the AuNPs and the cellular components responsible for their recognition and uptake.

\section{Acknowledgement}

The technical assistance of Mrs. Ana Margarida Silva is gratefully acknowledged.

\section{References}

[1] E. Boisselier, D. Astruc, Gold nanoparticles in nanomedicine: preparations, imaging, diagnostics, therapies and toxicity, Chem. Soc. Rev. 38 (2009) 17591782.

[2] D. Pissuwan, T. Niidome, M.B. Cortie, The forthcoming applications of gold nanoparticles in drug and gene delivery systems, J. Control. Release 149 (2011) 65-71.

[3] T. Kong, J. Zeng, X. Wang, X. Yang, J. Yang, S. McQuarrie, A. McEwan, W. Roa, J. Chen, J.Z. Xing, Enhancement of radiation cytotoxicity in breast-cancer cells by localized attachment of gold nanoparticles, Small 4 (2008) 1537-1543.

[4] A. Malugin, H. Ghandehari, Cellular uptake and toxicity of gold nanoparticles in prostate cancer cells: a comparative study of rods and spheres, J. Appl. Toxicol. 30 (2010) 212-217.

[5] G. Oberdorster, E. Oberdorster, J. Oberdorster, Nanotoxicology: an emerging discipline evolving from studies of ultrafine particles, Environ. Health Perspect. 113 (2005) 823-839.

[6] S.K. Balasubramanian, J. Jittiwat, J. Manikandan, C.N. Ong, L.E. Yu, W.Y. Ong, Biodistribution of gold nanoparticles and gene expression changes in the liver and spleen after intravenous administration in rats, Biomaterials 31 (2010) 2034-2042.

[7] W.H. De Jong, W.I. Hagens, P. Krystek, M.C. Burger, A.J. Sips, R.E. Geertsma, Particle size-dependent organ distribution of gold nanoparticles after intravenous administration, Biomaterials 29 (2008) 1912-1919.

[8] E. Sadauskas, G. Danscher, M. Stoltenberg, U. Vogel, A. Larsen, H. Wallin, Protracted elimination of gold nanoparticles from mouse liver, Nanomedicine 5 (2009) 162-169.

[9] G. Sonavane, K. Tomoda, K. Makino, Biodistribution of colloidal gold nanoparticles after intravenous administration: effect of particle size, Colloids Surf. B: Biointerfaces 66 (2008) 274-280.

[10] X.D. Zhang, H.Y. Wu, D. Wu, Y.Y. Wang, J.H. Chang, Z.B. Zhai, A.M. Meng, P.X Liu, L.A. Zhang, F.Y. Fan, Toxicologic effects of gold nanoparticles in vivo by different administration routes, Int. J. Nanomed. 5 (2010) 771-781.

[11] J.F. Hillyer, R.M. Albrecht, Gastrointestinal persorption and tissue distribution of differently sized colloidal gold nanoparticles, J. Pharm. Sci. 90 (2001) $1927-$ 1936.

[12] C. Schleh, M. Semmler-Behnke, J. Lipka, A. Wenk, S. Hirn, M. Sch Ffler, G.N Schmid, U. Simon, W.G. Kreyling, Size and surface charge of gold nanoparticles determine absorption across intestinal barriers and accumulation in secondary target organs after oral administration, Nanotoxicology (2011), doi:10.3109/ 17435390.2011 .552811$.

[13] W.S. Cho, M. Cho, J. Jeong, M. Choi, B.S. Han, H.S. Shin, J. Hong, B.H. Chung, J Jeong, M.H. Cho, Size-dependent tissue kinetics of PEG-coated gold nanoparticles, Toxicol. Appl. Pharmacol. 245 (2010) 116-123.

[14] W.S. Cho, M. Cho, J. Jeong, M. Choi, H.Y. Cho, B.S. Han, S.H. Kim, H.O. Kim, Y.T Lim, B.H. Chung, Acute toxicity and pharmacokinetics of $13 \mathrm{~nm}$-sized PEGcoated gold nanoparticles, Toxicol. Appl. Pharmacol. 236 (2009) 16-24.

[15] C. Lasagna-Reeves, D. Gonzalez-Romero, M.A. Barria, I. Olmedo, A. Clos, V.M. Sadagopa Ramanujam, A. Urayama, L. Vergara, M.J. Kogan, C. Soto, Bioaccumulation and toxicity of gold nanoparticles after repeated administration in mice, Biochem. Biophys. Res. Commun. 393 (2010) 649-655

[16] D.E. Owens 3rd, N.A. Peppas, Opsonization, biodistribution, and pharmacokinetics of polymeric nanoparticles, Int. J. Pharm. 307 (2006) 93102. 
[17] A.V. Vergoni, G. Tosi, R. Tacchi, M.A. Vandelli, A. Bertolini, L. Costantino, Nanoparticles as drug delivery agents specific for CNS: in vivo biodistribution, Nanomedicine 5 (2009) 369-377.

[18] R. Levy, Peptide-capped gold nanoparticles: towards artificial proteins, Chembiochem 7 (2006) 1141-1145.

[19] M.J. Kogan, I. Olmedo, L. Hosta, A.R. Guerrero, L.J. Cruz, F. Albericio, Peptides and metallic nanoparticles for biomedical applications, Nanomedicine (London) 2 (2007) 287-306.

[20] T. Niidome, M. Yamagata, Y. Okamoto, Y. Akiyama, H. Takahashi, T. Kawano, Y. Katayama, Y. Niidome, PEG-modified gold nanorods with a stealth character for in vivo applications, J. Control. Release 114 (2006) 343-347.

[21] G. Zhang, Z. Yang, W. Lu, R. Zhang, Q. Huang, M. Tian, L. Li, D. Liang, C. Li, Influence of anchoring ligands and particle size on the colloidal stability and in vivo biodistribution of polyethylene glycol-coated gold nanoparticles in tumor-xenografted mice, Biomaterials 30 (2009) 1928-1936.

[22] J. Lipka, M. Semmler-Behnke, R.A. Sperling, A. Wenk, S. Takenaka, C. Schleh, T. Kissel, W.J. Parak, W.G. Kreyling, Biodistribution of PEG-modified gold nanoparticles following intratracheal instillation and intravenous injection, Biomaterials 31 (2010) 6574-6581.

[23] S. Guerrero, E. Araya, J.L. Fiedler, J.I. Arias, C. Adura, F. Albericio, E. Giralt, J.L. Arias, M.S. Fernandez, M.J. Kogan, Improving the brain delivery of gold nanoparticles by conjugation with an amphipathic peptide, Nanomedicine (London) 5 (2010) 897-913.

[24] R. Levy, N.T. Thanh, R.C. Doty, I. Hussain, R.J. Nichols, D.J. Schiffrin, M. Brust, D.G. Fernig, Rational and combinatorial design of peptide capping ligands for gold nanoparticles, J. Am. Chem. Soc. 126 (2004) 10076-10084.

[25] B.V. Enustun, J. Turkevich, Coagulation of colloidal gold, J. Am. Chem. Soc. 85 (1963) 3317-3328.

[26] J. Kimling, M. Maier, B. Okenve, V. Kotaidis, H. Ballot, A. Plech, Turkevich method for gold nanoparticle synthesis revisited, J. Phys. Chem. B 110 (2006) 15700-15707.

[27] G.B. Fields, R.L. Noble, Solid phase peptide synthesis utilizing 9fluorenylmethoxycarbonyl amino acids, Int. J. Pept. Protein Res. 35 (1990) 161-214.

[28] S.S. Wang, p-Alkoxybenzyl alcohol resin and pprotected peptide fragments, J. Am. Chem. Soc. 95 (1973) 1328-1333.

[29] E. Kaiser, R.L. Colescott, C.D. Bossinger, P.I. Cook, Color test for detection of free terminal amino groups in the solid-phase synthesis of peptides, Anal. Biochem. 34 (1970) 595-598.

[30] W. Haiss, N.T. Thanh, J. Aveyard, D.G. Fernig, Determination of size and concentration of gold nanoparticles from UV-vis spectra, Anal. Chem. 79 (2007) 4215-4221.

[31] ILAR, Guide for the Care and Use of Laboratory Animals, National Academy Press, Washington DC, 1996.
[32] N.G. Bastus, E. Sanchez-Tillo, S. Pujals, C. Farrera, C. Lopez, E. Giralt, A. Celada, J. Lloberas, V. Puntes, Homogeneous conjugation of peptides onto gold nanoparticles enhances macrophage response, ACS Nano 3 (2009) 1335-1344.

[33] J.F. Hainfeld, D.N. Slatkin, T.M. Focella, H.M. Smilowitz, Gold nanoparticles: a new X-ray contrast agent, Br. J. Radiol. 79 (2006) 248-253.

[34] S. Harper, C. Usenko, J.E. Hutchison, B.L.S. Maddux, R.L. Tanguay, In vivo biodistribution and toxicity depends on nanomaterial size, surface functionalisation and route of exposure, J. Exp. Nanosci. 3 (2008) 195-206.

[35] A.M. Alkilany, C.J. Murphy, Toxicity and cellular uptake of gold nanoparticles: what we have learned so far?, J Nanopart. Res. 12 (2010) 2313-2333.

[36] S. Hirn, M. Semmler-Behnke, C. Schleh, A. Wenk, J. Lipka, M. Schaffler, S. Takenaka, W. Moller, G. Schmid, U. Simon, W.G. Kreyling, Particle sizedependent and surface charge-dependent biodistribution of gold nanoparticles after intravenous administration, Eur. J. Pharm. Biopharm. 77 (2011) 407-416.

[37] T. Laaksonen, O. Pelliniemi, B.M. Quinn, Stability and electrostatics of mercaptoundecanoic acid-capped gold nanoparticles with varying counterion size, Chem. Phys. Chem. 7 (2008) 2143-2149.

[38] H.S. Choi, W. Liu, P. Misra, E. Tanaka, J.P. Zimmer, B. Itty Ipe, M.G. Bawendi, J.V. Frangioni, Renal clearance of quantum dots, Nat. Biotechnol. 25 (2007) 11651170.

[39] M. Semmler-Behnke, W.G. Kreyling, J. Lipka, S. Fertsch, A. Wenk, S. Takenaka, G. Schmid, W. Brandau, Biodistribution of 1.4- and 18-nm gold particles in rats, Small 4 (2008) 2108-2111.

[40] I. Gomes, N.C. Santos, L.M.A. Oliveira, A. Quintas, P. Eaton, E. Pereira, R. Franco, Probing surface properties of cytochrome $\mathrm{c}$ at Au bionanoconjugates, J. Phys. Chem. C 112 (2008) 16340-16347.

[41] I. Olmedo, E. Araya, F. Sanz, E. Medina, J. Arbiol, P. Toledo, A. Alvarez-Lueje, E. Giralt, M.J. Kogan, How changes in the sequence of the peptide CLPFFD-NH can modify the conjugation and stability of gold nanoparticles and their affinity for beta-amyloid fibrils, Bioconjug. Chem. 19 (2008) 1154-1163.

[42] Y.S. Chen, Y.C. Hung, I. Liau, G.S. Huang, Assessment of the in vivo toxicity of gold nanoparticles, Nanoscale Res. Lett. 4 (2009) 858-864.

[43] G.S. Terentyuk, G.N. Maslyakova, L.V. Suleymanova, B.N. Khlebtsov, B.Y. Kogan, G.G. Akchurin, A.V. Shantrocha, I.L. Maksimova, N.G. Khlebtsov, V.V. Tuchin, Circulation and distribution of gold nanoparticles and induced alterations of tissue morphology at intravenous particle delivery, J. Biophoton. 2 (2009) 292302.

[44] P. Nativo, I.A. Prior, M. Brust, Uptake and intracellular fate of surface-modified gold nanoparticles, ACS Nano 2 (2008) 1639-1644.

[45] R.A. Sperling, W.J. Parak, Surface modification, functionalization and bioconjugation of colloidal inorganic nanoparticles, Philos. Trans. A: Math. Phys. Eng. Sci. 368 (2010) 1333-1383. 